\title{
Health inequalities: death by political means
}

\author{
Kamran Abbasi executive editor
}

The BMJ

Austerity does not result in a fair society or healthier lives. The evidence is clear after a decade of cuts to public expenditure.

"When a society is flourishing," says Michael Marmot, "health tends to flourish" (doi:10.1136/bmj.m693).

Marmot is well placed to make this judgment. His work on social determinants of health is internationally renowned and influential. In 2008, he was commissioned by the government to review what could be done to reduce health inequalities. Fair Society, Healthy Lives, better known as the Marmot review, was published in 2010 and recommended policies to act on social determinants of health throughout the life course.

In a new report, Marmot finds that gains in life expectancy have slowed dramatically in the past decade, and social inequalities are widening. Life expectancy for women in the most deprived areas in the north of England has declined. The societal effects on healthy life are even more marked.

These are alarming findings requiring urgent action. What is lacking is political commitment, because, as Marmot argues, health inequalities are not inevitable but stem from avoidable inequalities in society. Austerity is death by politics. Is this a message that Boris Johnson's government is willing to accept and act on?

The evidence doesn't just come from Marmot. A new report by the Nuffield Trust shows the difficulties that prisoners, including pregnant women, face in accessing secondary care (doi:10.1136/ bmj.m724). Women are giving birth in prison or on the way to hospital. A higher proportion of prisoners than the general population miss medical appointments. The challenge, like any social inequality, is a complex one.

One social paradox might be private healthcare, a system generally associated with wealth, privilege, and work benefits, but under renewed scrutiny after the report of the Paterson Inquiry. Michael Anderson and colleagues criticise poor reporting of activity and outcomes by private hospitals and call for urgent action to bring the independent sector in line with the standards set by the NHS (doi:10.1136/bmj.m577).

Transparency, openness, and data sharing are equally fundamental to solving the puzzle of covid-19, which has many missing pieces, according to a fast track research paper on the clinical characteristics (doi:10.1136/bmj.m606) and an accompanying editorial (doi:10.1136/bmj.m627). We need better high quality information, but the social media "infodemic" that blurs fact and fiction might be creating mass panic. "Panic," says Robert Peckham from the University of Hong Kong, "is a hair's breadth from prudent concern" (http://bit.ly/3a7uoAR).

When it comes to social determinants and health inequalities, perhaps we've had too much prudent concern? The time for necessary panic is now. 